\title{
Portal Pressure Impact on Clinical Outcome after Major Hepatectomy: A Systematic Review and Meta-Analysis
}

\author{
Jorge Humberto Gomes Carrapita ${ }^{1,6^{*}}$, Ana Margarida Abrantes ${ }^{2,3,4,5}$, Bernardo Sousa-Pinto ${ }^{7,8}$, \\ Jorge Nunes Santos ${ }^{6}$, Maria Filomena Botelho ${ }^{2,3,4,5}$, José Guilherme Tralhão ${ }^{3,4,5,9}$, Jorge Maciel Barbosa ${ }^{1,10}$
}

'General Surgery Department of Vila Nova de Gaia/Espinho Hospital, Portugal ${ }^{2}$ Biophysics Institute, Faculty of Medicine, University of Coimbra, Portugal ${ }^{3}$ Clinical Academic Center of Coimbra, Coimbra, Portugal ${ }^{4}$ Coimbra Institute for Clinical and Biomedical Research (iCBR) area of Environment Genetics and Oncobiology (CIMAGO), Faculty of Medicine, University of Coimbra, Portugal ${ }^{5} \mathrm{CNC}$. IBILI Consortium/Center for Innovative Biomedicine and Biotechnology (ClBB), University of Coimbra, 3000-548 Coimbra, Portugal Institute of Biomedical Sciences Abel Salazar, University of Oporto, Portugal ${ }^{7}$ MEDCIDS - Department of communityMedicine, Information and Health decision Sciences, Faculty of Medicine, University of Oporto, Portugal ${ }^{8}$ CINTESIS - Center for health technologyand Services Research, Oporto, Portugal ${ }^{9}$ Medicine School, University of Coimbra, Surgery A, Surgery Department of University Hospital (CHUC), Coimbra, Portugal

${ }^{10}$ Fernando Pessoa University, Oporto, Portugal

\author{
*Corresponding author: \\ Jorge Humberto Gomes Carrapita, MD \\ Rua Francisco Barreto, n'l 132. \\ 4150-339 Porto. Portugal \\ Telephone number: 00351918684749 \\ E-mail: jcarrapita@gmail.com
}

Abbreviations:

PHLF - posthepatectomy liver failure; PVP - portal venous pressure;

\section{ABSTRACT}

Aim of the study: To systematically review the evidence regarding the association between portal venous pressure (PVP) after hepatectomy and posthepatectomy liver failure (PLHF) or other postsurgical outcomes.

Materials and methods: We searched PubMed, Scopus and Web of Science for studies assessing post-hepatectomy PVP (or its variation) and reporting its association with PHLF or other postsurgical outcomes. We performed a random-effects meta-analysis for the association between development of PHLF and post-hepatectomy PVP and its variation. Heterogeneity was assessed using Q-Cochran test and 12 statistic. Quality assessment was performed considering ROBINS-1 Cochrane tool.

Results: Four studies, assessing 439 patients, met the eligibility criteria and were included in this systematic review. The meta-analyses, including 3 studies, demonstrated that patients developing PHLF did not have a significantly higher post-hepatectomy PVP when compared to the remainder $(1.98 ; 95 \% \mathrm{Cl}=-1.44-5.39 ; \mathrm{p}=0.256 ; \mathrm{I} 2=2 \%)$, but had a significantly higher PVP variation (increase) during hepatectomy $(1.65 ; 95 \% \mathrm{Cl}=1.15-2.15 ; \mathrm{p}<0.001 ; \mathrm{I}=0 \%)$. The quality of the studies allowed to consider the robustness of the conclusions as "median".

Conclusions: An increased PVP variation following hepatectomy associates with a higher risk of PHLF, but the same was not observed for the absolute value of post-hepatectomy PVP.

Key words: hepatobiliary surgery, liver, portal venous pressure, portal inflow modulation, posthepatectomy liver failure, meta-analysis

\section{INTRODUCTION}

Currently, major hepatectomy, traditionally defined as the resection of three
Received: 12.02 .2020

Accepted: 31.03 .2020 
or more hepatic segments, constitutes the standard treatment of many benign or malignant liver diseases (1). Over the past 15 years, there has been an increase in survival and a decrease in morbidity in patients undergoing major hepatectomy or liver transplantation (1-5). However, despite this advancement, posthepatectomy liver failure (PHLF), which mortality approaches $50 \%$, is still frequent (1). Currently, the key point of liver function recovery after a major hepatectomy is the liver's ability to regenerate $(4,6)$. Implementation of strategies to increase hepatic regeneration and prevent PHLF have shown promising results. Such strategies include selective portal embolization performed before major hepatectomy (7), and iterative hepatectomy. These strategies have allowed to achieve a new perspective, wherein limiting factor is not the size and location of the lesions, but the future liver reserve after hepatectomy (6).

Simultaneously to the development of these new strategies focused on liver regeneration, recent studies have suggested that hemodynamic factors of liver circulation, in particular excessive portal venous pressure (PVP) in the remaining hepatic volume, can cause severe endothelial sinusoidal injury followed by hepatic dysfunction $(1,4,6)$. However, despite these pathological mechanisms described in clinical and experimental models $(4,6,8-13)$, published experience about the clinical effects of portal hyperperfusion after major hepatectomy, and particularly its possible association with PHLF, has not been systematically reviewed. Therefore, in this study, we performed a systematic review of studies assessing posthepatectomy PVP (or its post-hepatectomy variation) and its association with occurrence of PHLF or other major complication events.

\section{MATERIAL AND METHODS}

\section{Search strategy and selection criteria}

We followed PRISMA statement(14) for conducting and reporting systematic reviews. The

research protocol was registered at the
International Prospective Register of Systematic Reviews with the following registration number: CRD42020135879.

We searched PubMed, Scopus and Web of Science in the last quarter of 2019, using the MeSH terms and keywords "portal venous pressure", "portal inflow modulation", "posthepatectomy liver failure" (complete query available in table 1).

The inclusion criteria consisted of studies assessing humans, measuring PVP after hepatectomy and assessing its association with PHLF or other outcomes, such as liver function deterioration and postoperative mortality. It was not applied any exclusion criteria based on the language or date of publication.

After duplicates removal, screening by title and abstract reading was independently performed by two authors. The full texts of potentially eligible studies were then independently assessed by two authors. Data from included studies were independently extracted by two authors, according to a previously built specific form. Missing data were requested to the authors of the primary study. Any disagreement was solved by consensus.

We extracted data that included the year of publication, study design (i.e., whether the study was prospective or retrospective), sample size, patients characteristics (mean and median age, sex ratio, body mass index, malign or benign diagnosis, functional status, and American Society of Anaesthesiologists (ASA) score), frequency of potentially patient-related factors of poor prognosis (malignancy, hepatitis, preoperative jaundice, preoperative cholangitis, cirrhosis, alcohol consumption, smoking, diabetes mellitus, obesity), frequency of surgical procedure-related factors associated with por prognosis (future liver remnant and intra-operative blood transfusion), procedures and techniques used, PVP values (including post-hepatectomy and pre-hepatectomy values and/or its variation) and methods used to measure it, defined PVP cut-off reported to be associated to worsening outcomes, frequency of patients developing PHLF (50/50 criteria and International Study Group of Liver Surgery (ISGLS) criteria) and

Table 1 - Search query - number of articles searched

\begin{tabular}{lcccc}
\hline Mesh terms & Pubmed & Scopus & Web of science & Total \\
\hline Portal venous pressure & 5088 & 4874 & 2853 & 12815 \\
\hline Portal inflow modulation & 31 & 58 & 112 & 201 \\
\hline Posthepatectomy liver failure & 301 & 538 & 395 & 1234 \\
\hline Total & 5420 & 5470 & 3360 & 14250 \\
\hline
\end{tabular}


respective PVP values, and also other outcomes whose association with PVP was measured including cytolysis and coagulation function, morbidity (ClavienDindo Score), mortality and survival.

\section{Risk of bias}

Quality assessment of primary studies was performed independently by two authors by applying the ROBINS-I tool (a Cochrane risk of bias tool to assess non-randomized studies) (15). The Cohen kappa statistic (16) was used to quantify agreement between the investigators. Disagreements between the authors over the risk of bias assessment were solved by consensus.

\section{Statistical analysis}

We were only able to quantitatively pool information for the comparison of post-hepatectomy PVP and PVP variation between patients developing and not developing PHLF. For studies not reporting the standard-deviation or standard-error for each group, the standard deviation of each group was extrapolated from the SD of the total. It was performed a randomeffects meta-analysis of mean differences following the restricted maximum likelihood method. Heterogeneity was assessed using both the Q-Cochran test and the $\mathrm{I}^{2}$ statistic - a Q-Cochran $\mathrm{p}$ value less than 0.10 , and an $\mathrm{I}^{2}$ greater than $50 \%$ were considered indicative of substantial heterogeneity. Software $\mathrm{R}$ (meta package) was used for statistical analysis. The significance threshold used was $p<0.05$.

\section{RESULTS}

\section{Literature search}

The process of study selection is illustrated in figure 1 (PRISMA flow diagram). A total of 3987 records were initially retrieved. After removing duplicates

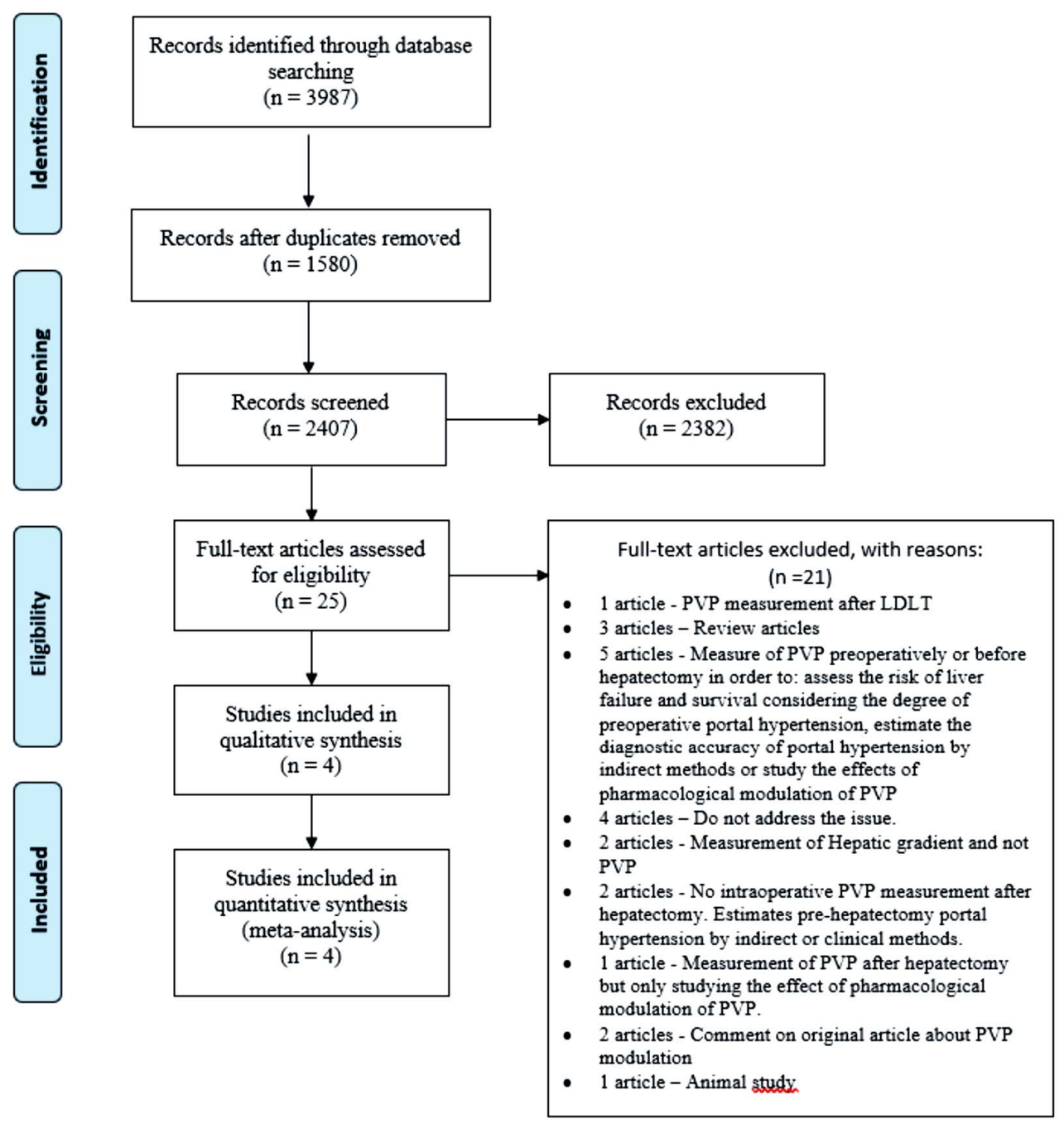


( $n=1580), 2407$ articles were screened. Among them, 2382 articles were excluded by title or abstract reading. Of the 25 studies fully read, 21 studies were excluded (17-37), so that 4 studies were included in this systematic review $(1,38-40)$.

\section{Characteristics and quality of included studies}

The characteristics of included studies are shown in table 2 and table 3. The 4 included studies were published between 2013 and 2019 and included a total of 439 patients. Three of those studies had a prospective design $(1,39,40)$.

Looking at the factors that may influence the study analysis, only two studies provided information on the body mass $(39,40)$, one included information on the functional status, ASA score and previous alcohol and smoking habits(39), three studies discriminated the percentage of patients with diabetes mellitus $(1,38,39)$, and all consider the extent of liver resection. Regarding the presence of cirrhosis, one study included 3 patients
CHILD A (40), two studies did not include cirrhotic patients $(1,39)$, while lida et al. did not explicitly report the percentage of cirrhotic patients, but all patients had an acceptable risk score including hepatic clearance function(38). The perioperative blood transfusion was considered in two studies $(1,39)$ and only one study included one patient submitted to two-stage hepatectomy (39). According to the ISGLS classification, 3 studies reported $10 \%, 37.5 \%$ and $13.4 \%$ of patients with PHLF grade B and C (38-40), while Allard et al only reported patients with PHLF grade $\mathrm{C}(10.5 \%)$.

In three studies portal venous pressure was measured by direct puncture of the portal vein using a needle/catheter attached to a transducer $(1,39,40)$, while in one study it was performed by introducing a tube into the round ligament (38). Three studies presented results for post-hepatectomy PVP values $(1,39,40)$, while PVP variation before and after hepatectomy was reported by three studies (38-40). One study concluded that increased PVP after hepatectomy is associated with deteriorated liver coagulation function (39). Considering only the risk of developing

Table 2 - Characteristics of the studies included in the systematic review

\begin{tabular}{|c|c|c|c|c|c|c|c|c|}
\hline $\begin{array}{l}\text { Study } \\
\text { (Publication Year) }\end{array}$ & Country & Design & Patients & $\begin{array}{c}\text { Age } \\
(\mu \pm S D)\end{array}$ & $\begin{array}{c}\text { Malignant } \\
\text { Diagnosis (\%) }\end{array}$ & $\begin{array}{c}\text { Cirrhosis Grade } \\
\text { (ISGLS Classification)(\%) }\end{array}$ & $\begin{array}{c}\text { Operative } \\
\text { procedures } \\
\text { (\% Major hepatectomy) }\end{array}$ & $\begin{array}{l}\text { ROBINS-I } \\
\text { Risk of bias } \\
\text { tool }\end{array}$ \\
\hline Allard et al (2013) & France & $\begin{array}{l}\text { Prospective } \\
\text { Randomized } \\
\text { Controlled }\end{array}$ & 277 & $52.7 \pm 16$ & $66 \%$ & $\begin{array}{c}\text { Grade C } \\
10,5 \%\end{array}$ & $100 \%$ & Low \\
\hline lida et al (2016) & Japan & Retrospective & 35 & $\begin{array}{c}\text { PHLF: } 60,1 \pm 12,7 \\
\emptyset: 64,1 \pm 8,1\end{array}$ & n.m. & $\begin{array}{c}\text { Grade B and C } \\
37,5 \%\end{array}$ & $\begin{array}{l}100 \% \\
\text { Right hepatectomy }\end{array}$ & Moderate \\
\hline Carrapita et al (2019) & Portugal & $\begin{array}{l}\text { Prospective } \\
\text { Controlled }\end{array}$ & 30 & $62.47 \pm 11.42$ & $76.67 \%$ & $\begin{array}{c}\text { Grade } B \text { and } C \\
10 \%\end{array}$ & $73,33 \%$ & Moderate \\
\hline Bogner et al (2019) & Germany & $\begin{array}{l}\text { Prospective } \\
\text { Controlled }\end{array}$ & 97 & $\begin{array}{l}\text { MH: } 61,4 \pm 11,8 \\
\text { CG: } 56,2 \pm 14,5\end{array}$ & $86,6 \%$ & $\begin{array}{c}\text { Grade B and C } \\
13,4 \%\end{array}$ & $69,1 \%$ & Moderate \\
\hline
\end{tabular}

$\mu$ : mean; SD: standard deviation; PHLF: Posthepatectomy liver failure; Uncomplicated group: Ø; n.m: not mentioned. MH: Major hepatectomy group CG: control group (minor hepatectomy)

Table 3 - Other variables considered in the studies

\begin{tabular}{|c|c|c|c|c|c|c|c|c|c|}
\hline $\begin{array}{l}\text { First author } \\
\text { name }\end{array}$ & Q & $\begin{array}{l}\text { Body mass } \\
\text { index }\end{array}$ & $\begin{array}{c}\text { Functional } \\
\text { status } \\
\text { (Karnofsky } \\
\text { index) }\end{array}$ & $\begin{array}{c}\text { ASA score } \\
\text { (Median) }\end{array}$ & $\begin{array}{c}\text { Alcohol } \\
\text { consumption }\end{array}$ & Smoking & $\begin{array}{c}\text { Diabetes } \\
\text { Mellitus }\end{array}$ & $\begin{array}{c}\text { Future } \\
\text { Liver }\end{array}$ & $\begin{array}{c}\text { Remnant } \\
\text { Peroperative } \\
\text { blood } \\
\text { transfusion }\end{array}$ \\
\hline Carrapita et al & $18: 12$ & $26,78 \pm 4,48$ & $100 \%$ & 2 & $2(6,67 \%)$ & $6(20 \%)$ & $7(23,33 \%)$ & $0,65 \pm 0,18$ & $9(30 \%)$ \\
\hline Allard et al & $142: 135$ & not reported & not reported & not reported & not reported & not reported & $23(8,3 \%)$ & not reported & $114(41,16 \%)$ \\
\hline Lida et al & not reported & not reported & not reported & not reported & not reported & not reported & $22,86 \%$ & not reported & not reported \\
\hline Bogner et al & $\begin{array}{l}\text { Major } \\
\text { Hepatectomy } \\
\text { Group: } \\
29: 38 \\
\text { Control } \\
\text { Group: } \\
\text { 16:14 }\end{array}$ & $\begin{array}{c}\text { Major } \\
\text { Hepatectomy: } \\
25,7 \pm 4,6 \\
\text { Minor } \\
\text { Hepatectomy: } \\
25,7 \pm 3,9\end{array}$ & not reported & not reported & not reported & not reported & not reported & not reported & not reported \\
\hline
\end{tabular}


Table 4 - results of the studies included in the systematic review

\begin{tabular}{|c|c|c|c|c|}
\hline $\begin{array}{l}\text { Study } \\
\text { (Publication Year) }\end{array}$ & $\begin{array}{l}\text { PVP cut off poor } \\
\text { prognosis }(\mathrm{mm} \mathrm{Hg})\end{array}$ & $\begin{array}{l}\text { Primary } \\
\text { outcome }\end{array}$ & Secondary outcome & Conclusions \\
\hline \multirow[t]{2}{*}{ Allard et al (2013) } & $\begin{array}{l}\text { PVP post hep } \geq 22 \\
\text { (PHLF grade C) }\end{array}$ & & $\begin{array}{l}\mathrm{PVP} \geq 22 \mathrm{mmHg} \text { is an } \\
\text { independent factor for the } \\
\text { occurrence of PHLF grade } \mathrm{C} \\
\text { (RR=4.24; } 95 \% \text { IC: } 1.89-16.40 ; \mathrm{P}<0.05 \text { ) }\end{array}$ & $\begin{array}{l}\Rightarrow \text { PVP post hep is an independent } \\
\text { predictive factor of PHLF and } 90 \text {-day } \\
\text { mortality after major liver resection } \\
\text { in patients without cirrhosis }\end{array}$ \\
\hline & $\begin{array}{l}\text { PVP post hep } \geq 21 \\
\text { (Mortality and } \\
\text { Bilirubin peak) }\end{array}$ & $\begin{array}{l}\text { Bilirubin peak greater } \\
\text { than } 120 \mu \mathrm{mol} / \mathrm{L}\end{array}$ & $\begin{array}{l}P V P \geq 21 \mathrm{mmHg} \text { is an independent factor } \\
\text { for mortality } \\
\text { (RR=5.37; } 95 \% \text { IC: } 1.87-15.39 ; P<0.05)\end{array}$ & $\begin{array}{l}\Rightarrow \text { PVP post hep } \geq 21 \mathrm{mmHg} \text { is the } \\
\text { cut off for worst outcome }\end{array}$ \\
\hline lida et al (2016) & $v \mathrm{PVP} \geq 2.2$ & - & $\begin{array}{l}v \mathrm{PVP} \geq 2.2 \mathrm{~mm} \mathrm{Hg} \text { is an independent factor } \\
\text { for the occurrence of } \mathrm{PHLF} \text { grade } \mathrm{B} \text { and } \mathrm{C} \\
\text { (OR=3.11;95\% IC: } 1.536-8.183 ; \mathrm{P}<0.05 \text { ) }\end{array}$ & $\begin{array}{l}\Rightarrow \text { PVP increase } \geq 2.2 \mathrm{mmHg} \\
\text { following right hepatectomy is a } \\
\text { risk factor for PHLF }\end{array}$ \\
\hline $\begin{array}{l}\text { Carrapita et al } \\
\text { (2019) }\end{array}$ & PVP post hep $\geq 12.5$ & $\begin{array}{l}\text { Deterioration of } \\
\text { coagulation at } 24 \mathrm{~h}, \\
5^{\text {th }} \text { and } 30^{\text {th }} \text { day }\end{array}$ & $\begin{array}{l}v \mathrm{PVP} \geq 2 \mathrm{~mm} \mathrm{Hg} \text { is an independent factor } \\
\text { for the occurrence of major complications } \\
\text { (OR=0.124; } 95 \% \text { IC: } 0.018-0.837 ; \mathrm{P}<0.05 \text { ) }\end{array}$ & $\begin{array}{l}\Rightarrow \text { PVP increase during hepatectomy } \\
\text { influences the deterioration of liver } \\
\text { function in the postoperative period } \\
\Rightarrow \text { A PVP increase } \geq 2 \mathrm{mmHg} \text { after } \\
\text { hepatectomy, compared to baseline, } \\
\text { rises the risk of major complications }\end{array}$ \\
\hline Bogner et al (2019) & - & $\begin{array}{l}\text { No association between } \\
v \text { PVP with any other } \\
\text { clinic-pathological variables }\end{array}$ & $\begin{array}{l}v \text { PVP has a significant and independent } \\
\text { association with PHLF Grade } B \text { and } C \\
\text { (OR=1.154; } 95 \% \text { IC: } 1.018-1.307 ; P<0.05) \\
\text { P }\end{array}$ & $\begin{array}{l}\Rightarrow \text { The extent of intraoperative PVP } \\
\text { increase was found as an immediate } \\
\text { and independent predictor of PHLF } \\
\Rightarrow v \text { PVP has higher predictive value } \\
\text { of PHLF than pure post resection } \\
\text { PVP value. }\end{array}$ \\
\hline
\end{tabular}

PVP post hep: Posthepatectomy portal venous pressure; PHLF: posthepatectomy liver failure; $v$ PVP: Portal venous pressure variation during hepatectomy;

Bilirubin peak: Peak of bilirubin greater than $120 \mu \mathrm{mol} / \mathrm{L}$.

PHLF, Allard et al defined a PVP cut off after hepatectomy of $22 \mathrm{mmHg}$ for the occurrence of grade $\mathrm{C}$ of this syndrome (RR= 4.24: 95\% IC: 1.88-16.40; $p<0.05)(1)$, while Carrapita et al found a PVP cut off after hepatectomy predicting PHLF (grade B and C) of $12.5 \mathrm{mmHg}$ (39), as shown in table 4. If it is considered the variation of PVP that occurs during hepatectomy, and not just the measurement of PVP at the end of hepatectomy, we detect a $2.2 \mathrm{mmHg}$ cut off as a predictor of PHLF grade $B$ and $C(O R=0.124 ; 95 \%$ IC: $0.018-0.837 ; p<0.05)$ in one study (38), and a $2,2 \mathrm{mmHg}$ cut off predicting major complications (OR= 0.124 ; 95\% IC: 0.018-0.837; $p<0.05$ ) (39). All studies concluded that the elevation of PVP after hepatectomy increases the risk of PHLF, according to the ISGLS criteria, as shown in table $2(1,38-40)$.

\section{Meta-analytical results}

Two studies compared patients with and without
PHLF on their post-hepatectomy PVP values $(39,40)$. Both studies reported a higher post-hepatectomy PVP mean value in the PHLF group when compared to the remaining patients. The pooled metaanalytical PVP mean difference between the two groups was not significantly different (1.98; 95\% $\mathrm{Cl}=-1.44 ; 5.39 ; \mathrm{p}=0.256)$, with no substantial heterogeneity detected ( $12=2 \% ; p=0.313$ ) (figure 2$)$.

All the three studies compared patients with and without PHLF on their post-hepatectomy PVP variation (38-40). All these studies reported a higher mean PVP increase in the PHLF group, comparing to the group without this postoperative complication. Patients developing PHLF had a significantly higher PVP increase compared to the remainder (1.65; $95 \% \mathrm{Cl}=1.15 ; 2.15 ; \mathrm{p}<0.001)$, with no heterogeneity detected ( $12=0 \% ; p=0.649$ ) (figure 3$)$.

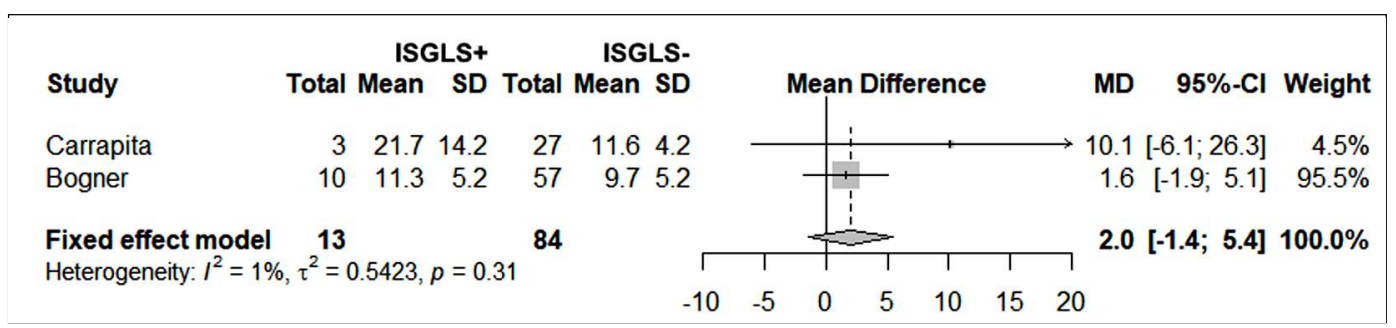

Figure 2 - Forestplot of pooled meta-analytical posthepatectomy portal venous pressure mean difference 


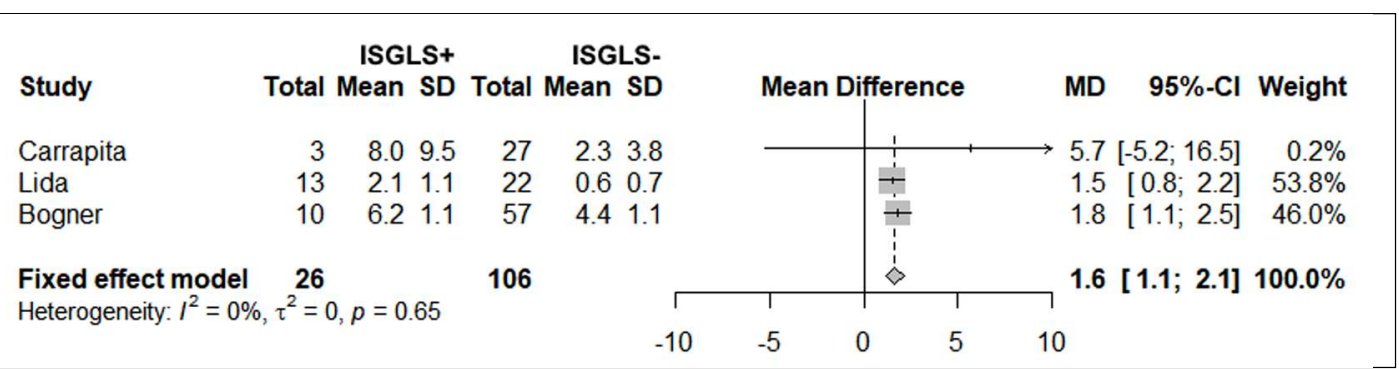

Figure 3 - Forestplot of pooled meta-analytical portal venous pressure variation mean difference

\section{Quality of studies}

Regarding the quality of the studies, the ROBINS-I tool, which is a Cochrane risk of bias tool to assess non-randomized studies of interventions expressed in table 2 and table 5, allowed to consider the included studies as having low or moderate risk of bias for all domains. It was found an increased risk of confounding bias in one study because of the high number of influencing factors included, although it was minimized by stepwise selection (39). Three studies present a risk of misclassification of exposure because they do not consider other factors that may influence the analysis studied, namely diseases and previous habits, functional status and perioperative blood transfusion $(1,38,40)$. The risk of performance bias was considered in three studies, because it was not explained if the surgical team was always the same, which was minimized by standardization of the procedure $(1,38,40)$. In addition, one study was considered to have limited internal validity because of its retrospective nature(38), while three studies were considered to have limited validity on account of their small sample size (38-40).

\section{DISCUSSION}

This systematic review suggests that patients who develop PHLF exhibit an increase in PVP during major hepatectomy which is significantly higher to that observed in patients who do not have this postoperative syndrome. This reinforces the importance of intraoperative measurement of PVP. On the other hand, this review suggests that the isolated measurement of PVP after hepatectomy is not enough, since this absolute value is not significantly different in groups with or without PHLF. In addition, in this review the cut off variance found in the studies included was explicit, if only the measurement of PVP after hepatectomy is considered. Probably, the difference in the PVP cut off after hepatectomy predicting PHLF observed in the two included studies ( $22 \mathrm{mmHg}$ versus $12.5 \mathrm{mmHg}$ ) is not only be related to the difference in the inclusion criteria of patients with PHLF (grade $C$ versus grade $B$ and $C$ ). This discrepancy reflects the variability of PVP to which several factors contribute, namely the PVP before hepatectomy.

Besides the clinical studies assessed in this systematic review, there are also experimental studies, explaining the pathological processes underlying the association between PVP increase and PHLF (1,6,10-12). These studies allowed to clarify some mechanisms through which the portal venous hyperperfusion induces deleterious effects on the liver parenchyma, particularly the increase in cell death by apoptosis and oxidative

Table 5 - Risk of bias ROBINS-I assessment tool

(Cochrane risk of bias tool to assess non-randomized studies)

\begin{tabular}{|c|c|c|c|c|}
\hline & $\begin{array}{c}\text { Allard et al } \\
(2013)\end{array}$ & $\begin{array}{c}\text { lida et al } \\
\text { (2016) }\end{array}$ & $\begin{array}{c}\text { Carrapita et al } \\
\text { (2019) }\end{array}$ & $\begin{array}{c}\text { Bogner et al } \\
(2019)\end{array}$ \\
\hline Bias due to confounding & Moderate & Moderate & Moderate & Moderate \\
\hline Bias in selection of participants into the study & Low & Low & Low & Moderate \\
\hline Bias in classification of interventions & Low & Moderate & Low & Low \\
\hline Bias due to deviations from intended interventions & Low & Low & Low & Low \\
\hline Bias due to missing data & Low & Moderate & Low & Low \\
\hline Bias in measurement of outcomes & Low & Low & Low & Low \\
\hline Bias in selection of the reported result & Moderate & Moderate & Moderate & Moderate \\
\hline Overall bias & Low & Moderate & Moderate & Moderate \\
\hline
\end{tabular}


stress mediated by humoral and inflammatory response.

Furthermore, it is now known that the transhepatic flow regulation mechanism, which is equal to hepatic arterial flow plus portal venous flow, is related to the so-called artery buffer response, which allows to compensate an elevation of the portal venous flow with a constriction of the hepatic artery, mediated by the decrease of the adenosine phosphatase concentration (so-called "adenosine washout hypothesis") (28). The problem arises when this mechanism is not enough to compensate the abrupt and sharp rise in portal pressure/flow, particularly in the presence of liver injury, namely steatosis, cirrhosis, prolonged exposure to chemotherapeutic agents or prolonged intraoperative ischemia. In these circumstances, the tolerance threshold for portal hyperperfusion is decreased, resulting in need for greater future liver remnant $(4,13)$. This can explain the need for a greater graft volume in cirrhotic patients, whose over dynamic circulation status could result, with higher probability, in liver failure after LDLT (4).

Currently, in LDLT, targets have been met to establish criteria to define in which situations the risk of graft liver failure is increased. For this purpose, much contributed Govil et al. (41), which confirmed the achievements of previous studies and proposed recommendations. They presented the concept of small-for-flow, confirming that graft dysfunction, although multifactorial, is associated with high portal pressure and flow, establishing limits to portal flow and pressure in order to avoid this syndrome and suggested that both should be considered to avoid the portal steal syndrome. In addition, these authors suggest that, in LDLT, a portal flow greater than 4 times the right portal vein flow of the donor (that is $>360 \mathrm{ml} / \mathrm{min}$ per $100 \mathrm{~g}$ graft weight) or the combination of PVP $>15 \mathrm{mmHg}$ and a portal flow greater than 2 times the basal flow of the right portal vein of the donor (that is $>180 \mathrm{ml} / \mathrm{min}$ per $100 \mathrm{~g}$ graft weight), significantly increases the risk of small-for-flow syndrome (41). However, such indications are not yet supported by adequate scientific evidence. This review has some limitations, namely the limited number of studies, rendering it impossible to perform subgroup analysis or meta-regression. Nevertheless, the need for such methods is curbed by the low heterogeneity observed. In addition, the high number of factors which predispose to PHLF and could influence the PVP/PHLF relation, besides not being all described in all the studies, may promote the occurrence of confounding. Another limitation is the small number of patients participating in each study included in this review, resulting in decreased precision of the obtained estimates. Additional limitations include the disparity in the design and methodology of published studies, namely the inclusion of patients with different grades of liver failure after hepatectomy, the adoption of different PVP predictive cut-offs of PHLF, and lack of information on outcomes other than PHLF, such as mortality.

However, despite these limitations, this systematic review has also some strengths. In particular, its search was performed in three different bibliographic databases, with no definition of exclusion criteria based on publication language or date. This is the first systematic review with meta-analysis assessing the association between PVP and PHLF, and points to the potential importance of assessing PVP during hepatectomy, by assessing the relative increase in PVP during hepatectomy, rather than the absolute value of PVP measured after hepatectomy. Taking this into account, future research should try to define cut off(s) of PVP increment corresponding to relevant increases in the risk of PHLF. This would contribute to define indications of portal influx modulation, with the goal of decreasing the incidence of PHLF and, therefore, mortality after major hepatectomy.

\section{CONCLUSION}

The relative increase in PVP during hepatectomy is associated with increased occurrence of PHLF, contrarily to what has been observed for the absolute value of PVP after hepatectomy. Standardizing the methodology for PVP measurement and defining PVP variance cut-offs, not only may allow to predict which patients may be in increased risk of PHLF, but also opens a door to the implementation of strategies for portal inflow modulation.

\section{Acknowledgements}

\section{Álvaro Martin for English grammar and word correction.}

\section{Disclosure of interest}

The authors report no conflict of interest.

\section{Funding}

This systematic review and meta-analysis were neither funded nor benefited by any organization or company.

\section{REFERENCES}

1. Allard M-A, Adam R, Bucur P-O, Termos S, Cunha AS, Bismuth H, 
et al. Posthepatectomy portal vein pressure predicts liver failure and mortality after major liver resection on noncirrhotic liver. Ann Surg. 2013;258(5):822-9; discussion 829-30.

2. Belghiti J, Kianmanesh R. Surgical treatment of hepatocellular carcinoma. HPB (0xford). 2005;7(1):42-9.

3. Balzan S, Belghiti J, Farges 0, Ogata S, Sauvanet A, Delefosse D, et al. The "50-50 Criteria" on Postoperative Day 5: An Accurate Predictor of Liver Failure and Death After Hepatectomy. Ann Surg. 2005;242(6):824-8, discussion 828-9.

4. Asencio JM, García Sabrido JL, Olmedilla L. How to expand the safe limits in hepatic resections? J Hepatobiliary Pancreat Sci. 2014; 21(6):399-404.

5. Wagener G. Assessment of hepatic function, operative candidacy, and medical management after liver resection in the patient with underlying liver disease. Semin Liver Dis. 2013;33(3):204-12.

6. Asencio JM, Vaquero J, Olmedilla L, García Sabrido JL. 'Smallfor-flow' syndrome: shifting the 'size' paradigm. Med Hypotheses. 2013;80(5):573-7.

7. Farges 0, Belghiti J, Kianmanesh R, Regimbeau JM, Santoro R, Vilgrain V, et al. Portal vein embolization before right hepatectomy: prospective clinical trial. Ann Surg. 2003;237(2):208-17.

8. Fondevila C, Hessheimer AJ, Taurá P, Sánchez O, Calatayud D, de Riva N, et al. Portal hyperperfusion: mechanism of injury and stimulus for regeneration in porcine small-for-size transplantation. Liver Transpl. 2010;16(3):364-74.

9. Hernandez-Gea V, Turon F, Berzigotti A, Villanueva A. Management of small hepatocellular carcinoma in cirrhosis: focus on portal hypertension. World J Gastroenterol. 2013;19(8):1193-9.

10. Tralhăo JG, Abrantes AM, Hoti E, Oliveiros B, Cardoso D, Faitot F, et al. Hepatectomy and liver regeneration: from experimental research to clinical application. ANZ J Surg. 2014;84(9):665-71.

11. Mortensen KE, Conley LN, Hedegaard J, Kalstad T, Sorensen P, Bendixen $C$, et al. Regenerative response in the pig liver remnant varies with the degree of resection and rise in portal pressure. Am J Physiol Gastrointest Liver Physiol. 2008;294(3):G819-30.

12. Leng J, Xing H, Tan J, Chen K, Dong J. The safe minimally ischemic liver remnant for small-for-size syndrome in porcine hepatectomy. Transplant Proc. 2013;45(6):2419-24.

13. Eshkenazy R, Dreznik Y, Lahat E, Zakai BB, Zendel A, Ariche A. Small for size liver remnant following resection: prevention and management. Hepatobiliary Surg Nutr. 2014;3(5):303-12.

14. Moher D, Liberati A, Tetzlaff J, Altman DG. Preferred reporting items for systematic reviews and meta-analyses: the PRISMA statement. BMJ. 2009;339(jul21 1):b2535-b2535

15. Sterne JA, Hernán MA, Reeves BC, Savović J, Berkman ND, Viswanathan M, et al. ROBINS-l: a tool for assessing risk of bias in non-randomised studies of interventions. BMJ. 2016 Oct 12;i4919.

16. Tang W, Hu J, Zhang H, Wu P, He H. Kappa coefficient: a popular measure of rater agreement. Shanghai Arch psychiatry. 2015; 27(1):62-7.

17. Osman AMA, Hosny AA, El-Shazli MA, Uemoto $S$, Abdelaziz 0 , Helmy AS. A portal pressure cut-off of 15 versus a cut-off of 20 for prevention of small-for-size syndrome in liver transplantation: A comparative study. Hepatol Res. 2017;47(4):293-302.

18. Famularo S, Gianotti L, Riggio 0 . Small-for-flow liver failure after extended hepatectomy: hot questions and an update. Gastroenterol Insights. 2017;8(1).

19. Lafaro K, Buettner S, Maqsood H, Wagner D, Bagante F, Spolverato G, et al. Defining Post Hepatectomy Liver Insufficiency: Where do We stand? J Gastrointest Surg. 2015;19(11):2079-92.

20. Marasco G, Colecchia A, Dajti E, Ravaioli F, Cucchetti A, Cescon M, et al. Prediction of posthepatectomy liver failure: Role of SSM and LSPS. J Surg Oncol. 2019;119(3):400-1.

21. Mohkam K, Darnis B, Mabrut J-Y. Hepatic Hemodynamic Changes After Liver Resection: a Reflection of the Complex Relationship Between Portal Vein Flow, Hepatic Artery Flow and Portal Pressure. J Gastrointest Surg. 2016;20(12):2107-8.

22. Pelegrina A, Martí J, Miquel R, Ferrer J, Hernández-Gea V, Diaz A, et al. Changes of liver hemodynamic and elastography parameters in patients with colorectal liver metastases receiving preoperative chemotherapy: "a note of caution". World J Surg Oncol. 2017; 15(1):224.

23. Rahnemai-Azar AA, Cloyd JM, Weber SM, Dillhoff M, Schmidt C, Winslow ER, et al. Update on Liver Failure Following Hepatic Resection: Strategies for Prediction and Avoidance of Post-operative Liver Insufficiency. J Clin Transl Hepatol. 2018;6(1):1-8

24. Rhaiem R, Piardi T, Chetboun M, Pessaux P, Lestra T, Memeo R, et al. Portal Inflow Modulation by Somatostatin After Major Liver Resection. Ann Surg. 2018;267(6):e101-3.

25. Nanashima A, Abo T, Arai J, Tominaga T, Takagi K, Mochinaga K, et al. Prediction of portal pressure from intraoperative ultrasonography. J Surg Res. 2014;192(2):395-401.

26. Robles-Campos R, Brusadin R, López-Conesa A, López-López V, Parrilla P. Portal Inflow Modulation by Somatostatin During Major Liver Resection With a High Risk of Postoperative Liver Failure. Ann Surg. 2018;267(6):e104.

27. Sand Bown L, Ricksten S-E, Houltz E, Einarsson H, Söndergaard S, Rizell M, et al. Vasopressin-induced changes in splanchnic blood flow and hepatic and portal venous pressures in liver resection. Acta Anaesthesiol Scand. 2016;60(5):607-15.

28. Golriz M, El Sakka S, Majlesara A, Edalatpour A, Hafezi M, Rezaei N, et al. Hepatic Hemodynamic Changes Following Stepwise Liver Resection. J Gastrointest Surg. 2016;20(3):587-94.

29. Capussotti L, Ferrero A, Viganò L, Muratore A, Polastri R, Bouzari H. Portal Hypertension: Contraindication to Liver Surgery? World J Surg. 2006;30(6):992-9.

30. Golriz M, Majlesara A, Khajeh E, Mehrabi A. Reply: Hepatic Hemodynamic Changes Following Stepwise Liver Resection (Golriz et al. J Gastrointest Surg (2016) 20:587-594). J Gastrointest Surg. 2016;20(12):2109-10.

31. Cauchy F, Soubrane 0, Belghiti J. Liver resection for HCC: patient's selection and controversial scenarios. Best Pract Res Clin Gastroenterol. 2014;28(5):881-96.

32. Cucchetti A, Cescon M, Golfieri R, Piscaglia F, Renzulli M, Neri F, et al. Hepatic venous pressure gradient in the preoperative assessment of patients with resectable hepatocellular carcinoma. J Hepatol. 2016;64(1):79-86.

33. Chen $X$, Zhai J, Cai X, Zhang Y, Wei L, Shi L, et al. Severity of portal hypertension and phild-Pugh grade A cirrhosisrediction of postoperative liver failure after liver resection in patients with $\mathrm{C} . \mathrm{Br} \mathrm{J}$ Surg. 2012:99(12):1701-10.

34. Hidaka M, Takatsuki M, Soyama A, Tanaka T, Muraoka I, Hara T, et al. Intraoperative portal venous pressure and long-term outcome after curative resection for hepatocellular carcinoma. $\mathrm{Br} \mathrm{J}$ Surg. 2012;99(9):1284-9.

35. Garcea G, Maddern GJ. Liver failure after major hepatic resection. J Hepatobiliary Pancreat Surg. 2009;16(2):145-55.

36. Giannini EG, Savarino V, Farinati F, Ciccarese F, Rapaccini G, Marco $\mathrm{M} \mathrm{Di}$, et al. Influence of clinically significant portal hypertension on survival after hepatic resection for hepatocellular carcinoma in cirrhotic patients. Liver Int. 2013;33(10):1594-600.

37. Skrzypczyk C, Truant S, Duhamel A, Langlois C, Boleslawski E, Hebbar M, et al. Comparison of Binary Predictive Scoring Systems of Posthepatectomy Liver Failure: A Response. Ann Surg. 2017;265(4):e57-8.

38. lida H, Aihara T, Ikuta S, Yamanaka N. Portal Vein Pressure Change Predicts Posthepatectomy Liver Failure Following Right Lobectomy. Int Surg. 2016;101(9-10):437-42.

39. Carrapita JG, Rocha C, Donato H, Costa A, Abrantes AM, Santos JN, et al. Portal Venous Pressure Variation during Hepatectomy: A Prospective Study. Acta Med Port. 2019;32(6):420.

40. Bogner A, Reissfelder C, Striebel F, Mehrabi A, Ghamarnejad O, Rahbari M, et al. Intraoperative Increase of Portal Venous Pressure is an Immediate Predictor of Posthepatectomy Liver Failure After Major Hepatectomy. Ann Surg. 2019 Jul 25. doi: 10.1097/SLA.0000000000003496. Online ahead of print.

41. Govil S, Reddy MS, Rela M. Has "Small-for-Size" Reached Its "Sell-By" Date. Transplantation. 2016;100(11):e119. 